\title{
Development of Energy Demand Estimation Model of Japanese Commercial Building Considering Diversity of Energy Conservation Measures
}

\author{
Takuya Kitamura, Yohei Yamaguchi, Bumjoon Kim, Kotone Akizawa, Yoshiyuki Shimoda \\ Graduate School of Engineering, Osaka University, M3 Building, 2-1 Yamadaoka, Suita, Osaka, \\ 565-0871, Japan
}

\begin{abstract}
Various energy conservation measures have been adopted for commercial buildings. However, urban building energy models (UBEMs) have not well addressed the heterogeneity of the stock in terms of adopted energy conservation measures. This paper proposes a logistic regression based method for considering energy conservation measures in a UBEM using building archetypes. A case study using the Japanese commercial building stock confirmed the existence of heterogeneity in the adopted energy conservation measures. An unawareness of this heterogeneity would have a significant impact on the estimated energy demand of the building stock.
\end{abstract}

\section{Introduction}

Various energy conservation measures have been adopted for commercial buildings to improve their energy performance. The energy conservation measures adopted for building stock are an important factor in understanding and modelling a building's energy performance. The enhancement of a building's insulation performance is a measure that has been well studied. This is because the insulation performance has a significant impact on a building's energy performance, and large quantities of insulation performance data are available in many countries. In urban building energy models (UBEMs), which quantify the energy consumption of buildings at an urban scale, effective methods have been established to address the heterogeneity of a building's insulation performance (Swan et al. 2009). On the other hand, most of the other energy conservation measures have not been well addressed in UBEMs.

The main reason for the success in considering a building's insulation performance in a UBEM is the fact that the insulation performance can be quantified as a continuous variable, i.e. a U-value. This enables modelling a building's insulation performance in the form of a probability distribution, from which a certain value can be sampled. This also allows building stock to be segmented. On the other hand, there are many energy conservation measures that cannot be adopted as continuous variables. The selection of such an energy conservation measure can be modelled as a dichotomous variable ( 0 or 1$)$ representing buildings with and without the measure. An example is the adoption of a total heat exchanger for a ventilation system. The adoption of a measure represented by a dichotomous variable can be modelled using a binomial logit (BNL) model. In BNL, the adoption probability, $p$, is given by Equations (1) and (2), where $\beta_{0}$ is an intercept, and $\beta_{n}$ is a regression coefficient of predictor variable $x_{n}(n=1$ to $N)$ :

$$
\begin{aligned}
& \ln \frac{p}{1-p}=\beta_{0}+\sum_{n=1}^{N} \beta_{n} \cdot x_{n} \\
& p=\frac{1}{1+\exp \left\{-\left(\beta_{0}+\sum_{n=1}^{N} \beta_{n} \cdot x_{n}\right)\right\}}
\end{aligned}
$$

A multinomial logit model (MNL) is typically applied when there are three or more choices, as shown in Equation (3), where $p_{i}$ is the probability of selecting choice $i$ :

$$
\ln \frac{p_{i}}{p_{\text {ref }}}=\beta_{0, i}+\sum_{n=1}^{N} \beta_{n, i} \cdot x_{n}
$$

where $p_{\text {ref }}$ is the $p_{i}$ value of a category that is used as a reference, called a reference category. Several studies have used BNL and MNL to model the adoption of technologies in building stock. Kontokosta (2016) applied the BNL model to analyse the adoption of energy retrofit measures in office buildings located in the US. Andrew and Krogmann (2009) applied the MNL model to model the adoption of energy efficient technologies in commercial buildings in the US. Jridi et al. (2015) applied the MNL model to model the adoption of energy conservation measures in Tunisian residential buildings. Yamaguchi et al. (2017) applied both BNL and MNL models for the stock of HVAC systems in the Japanese commercial building sector.

However, this approach is not efficient when the number of considered measures increases in the UBEM because the number of combinations of energy conservation measures increases exponentially. To the best of the authors' knowledge, few studies have addressed this issue. One approach to address these measures is to use a typical combination of energy conservation measures. In Kimura et al. (2017), the adoption of a total heat exchanger was assumed in simulated buildings. Second, several segments of the building stock can be considered with different combinations of energy conservation measures. Yamaguchi et al. (2007) considered five segments, and the proportions of the segments were given based on sample data. Fernandez et al. (2018) modelled the adoption of energy conservation measures as three segments, namely efficient, typical, and inefficient buildings for commercial building stock in the US. The proportions of these segments were $30 \%, 50 \%$, and $20 \%$, respectively. However, these proportions were based on 
an expert's judgement instead of statistical data representing reality.

Based on this background, this study had the goal of developing a method to address the heterogeneity in the adoption of energy conservation measures in a UBEM. The next section proposes a stock modelling method that considers the heterogeneity. Then, the proposed method is applied to the Japanese commercial building sector. Finally, a method to incorporate the stock modelling result in a UBEM of the sector is presented. The model is used to evaluate how the proposed method contributes to improving the accuracy of the estimated energy demand.

\section{Method}

The proposed method comprises three steps. Figure 1 shows an overview of the method. The method is an extension of the method established in Yamaguchi et al. (2017), which was developed to quantify the composition of the Japanese commercial building stock in terms of the configurations of heat source systems. The first step identifies the major combinations of energy conservation measures that have frequently been selected for buildings. The identified combinations are used to classify the building stock in the following steps. The second step develops BNL or MNL models based on sample data to quantify the probabilities of selecting the identified combinations when an arbitrary building is newly constructed or renovated. Finally, the building stock is disaggregated into groups with the various combinations of energy conservation measures by applying the developed BNL or MNL models to the building stock data. Sample data for buildings with the adopted energy conservation measures are necessary for the first and second steps. In the third step, data showing the composition of the building stock are used.

The following subsections explain the processes in detail.

\section{Identification of major combinations of energy conservation measures}

The combinations of energy conservation measures are identified using an association analysis, or the so-called Apriori algorithm (Agrawal et al. 1994). The Apriori algorithm is widely used to identify the relationships among items within a given dataset. An example was given in Wang et al. (2018). In this algorithm, three types of evaluation indices are considered, namely, the support shown in Equation (4), the confidence in Equation (5), and the lift in Equation (6).

$$
\begin{gathered}
\operatorname{support}(X \Rightarrow Y)=\frac{\sigma(X \cup Y)}{M} \\
\operatorname{confidence}(X \Rightarrow Y)=\frac{\sigma(X \cup Y)}{\sigma(X)} \\
\operatorname{lift}(X \Rightarrow Y)=\frac{\operatorname{confidence}(X \Rightarrow Y)}{\operatorname{support}(Y)}
\end{gathered}
$$

$X$ and $Y$ are combinations of two dichotomous variables in the sample, and $\sigma(X)$ indicates the number of samples containing $X=1$. $M$ is the total sample size. The support value represents the occurrence frequency of the combination of $X$ and $Y$ (i.e. $X=1$ and $Y=1$ ) in the sample. The combination is referred to as the association rule. The confidence value represents the strength of the relation between $X$ and $Y$. Using the association rule, the occurrence of $Y$ can be predicted based on the occurrence of $X$. Generally, a threshold value is used to determine whether or not association rules are effective.

The algorithm enables us to identify combinations of energy conservation measures that are frequently observed in sample buildings. In this study, we considered the adoption of an energy conservation measure using a dichotomous variable. The combinations with support values larger than 0.16 were identified as the combinations considered in the stock modelling because these combinations could be considered to have significant proportions in the stock.

\section{Logistic regression modelling}

The probabilities of adopting the combinations of energy conservation measures identified in the previous step for a building were modelled by logit models based on sample data. A BNL model was used when there were only two combinations, whereas an MNL model was used when there were three or more combinations. In the

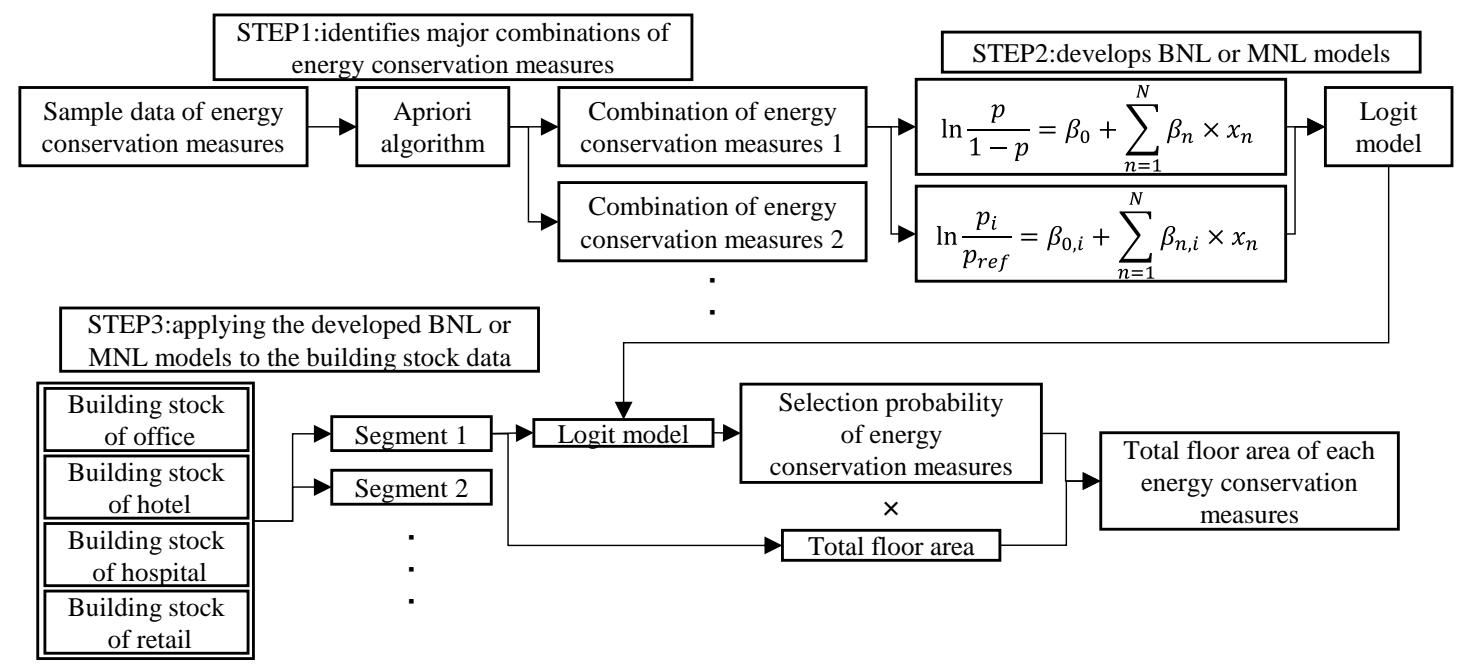

Figure 1: Overview of method. 
regression analysis, numerous predictor variables with significant influences on the selection probability were considered. As a result, the developed logit models quantified the probabilities of adopting the considered combinations of energy conservation measures at an arbitral building with the conditions given by the predictor variables.

\section{Estimation of composition of building stock}

The developed logit models were used to estimate the composition of the building stock in terms of the combinations of energy conservation measures identified in the first step. This step used building stock data, where the composition of the building stock could be disaggregated by the predictor variables used in the BNL and MNL models. First, the total building stock was disaggregated by the combinations of predictor variables. Then, the mean values of the predictor variables in each building stock segment were quantified. The mean values were input to the BNL and MNL models to quantify the selection probabilities of the combinations of energy conservation measures. The total floor area adopting each combination was quantified for each building stock segment by multiplying the selection probability by the total floor area in the building stock segment. Finally, the total building stock was estimated by aggregating the total floor area of the buildings that were identified as adopting the combinations of energy conservation measures.

\section{Application to Japanese commercial building sector}

This section explains the application of the method described in the previous section to the Japanese office, hotel, hospital, and retail building stock. In the following subsections, the data used in the study are first explained, followed by the application results.

\section{Data used in first and second steps}

We used the ELPAC database, which has been published by the Japanese Association of Building Mechanical and Electrical Engineers (JABMEE) since 1984. The ELPAC data include information about construction specifications and the electrical, HVAC, and sanitary facilities of buildings renovated or newly constructed from 1984 to 2016. Surveys were conducted for office, hotel, hospital, retail, and other special use buildings in sequence each year. A total of 3390 data samples were used in the analysis.

Table 1 lists the energy conservation measures considered in this study. Figure 2 shows the number of buildings that adopted these energy conservation measures. The figure shows higher adoption rates for the total heat exchanger, natural ventilation, and outside air intake control.

We used the predictor variables listed in Table 2. The predictor variables were the same as those used by Yamaguchi et al. (2017), where BNL and MNL models were developed for the heat source system of the HVAC system, with the exception of the kinds of air-conditioning systems. This study considered the kinds of airconditioning system to determine their influences on the adoption of the energy conservation measures.

\section{Data used in third step}

We used the building construction survey data (BCSD) provided by the Ministry of Land, Infrastructure, Transport, and Tourism of Japan and the geographical information system (GIS) database published by ESRI. The BSCD contains information about the total floor area and number of buildings of the Japanese commercial building stock located in each prefecture, disaggregated by the building size, use, and year of completion. The GIS database contains information about the location, building use, and floor area of each building. Step 3 of Figure 1 illustrates the method. First, the data of each building contained in the GIS database were classified into building stock segments based on the building location, size, and use. Second, we prepared the values of the

Table 1: List of energy conservation measures.

\begin{tabular}{|c|c|}
\hline $\begin{array}{l}\text { Category } \\
\text { Number }\end{array}$ & Energy conservation measures \\
\hline ES1 & $\begin{array}{c}\text { Adoption of total heat exchanger in ventilation } \\
\text { system }\end{array}$ \\
\hline ES2 & Natural ventilation \\
\hline ES3 & Outdoor air cooling system \\
\hline ES4 & $\begin{array}{l}\text { Variable water volume (VWV) control in } \\
\text { water delivery system }\end{array}$ \\
\hline ES5 & $\begin{array}{c}\text { Ventilation volume control based on } \mathrm{CO}_{2} \\
\text { concentration }\end{array}$ \\
\hline ES6 & Natural cross-ventilation \\
\hline ES7 & $\begin{array}{l}\text { Use of a wider water temperature difference in } \\
\text { water delivery system }\end{array}$ \\
\hline ES8 & $\begin{array}{c}\text { Use of a wider air temperature difference in } \\
\text { air-conditioning system }\end{array}$ \\
\hline ES9 & Night-time ventilation \\
\hline \multirow[b]{2}{*}{ 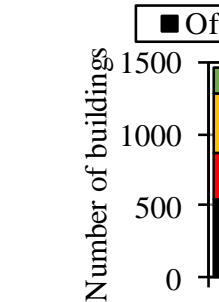 } & 口Office $\square$ Hotel $\square$ Hospital $\square$ Retail \\
\hline & 0 \\
\hline
\end{tabular}

Figure 2: Frequencies of energy conservation measures.

Table 2: List of predictor variables.

\begin{tabular}{cc}
\hline Abbreviation & Variables \\
\hline LogTFA & Log10 of building total floor area \\
Year1 & Binary variable indicating the year of \\
Year2 & construction \\
Year3 & Year1: 1984-1989 \\
Year4 & Year2: 1990-1999 \\
& Year3: 2000-2009 \\
HDD & Year4: 2010-2017 \\
PD & Heating degree days \\
MUL & Population density of municipality \\
CAV & Binary variable indicating the type of \\
VAV & HVAC system \\
FCU & MUL: Multiple Indoor Units \\
OHUFCU & CAV: Constant Air Volume \\
& VAV: Variable Air Volume \\
& FCU: Fan Coil Unit \\
& OHUFCU: Outdoor Handling Unit and \\
\end{tabular}


predictor variables for each building stock category to apply the logit models developed in the previous section to the Japanese commercial building stock. The building total floor area predictor variable was prepared from the floor area information contained in the GIS database. The heating degree-days predictor variable was prepared from the meteorological data measured at the meteorological observatory of each prefecture. The population density of the municipality predictor variable was prepared from the population census of the municipality according to information about the location of each building contained in the GIS database. The year of construction predictor variable was prepared from the BCSD. The proportions of the building stock with the considered kinds of airconditioning systems were also quantified, as mentioned below. Finally, we estimated the stock of the energy conservation measures by multiplying the selection probability of the energy conservation measures estimated in the second step and the total floor area of each building stock segment classified in the first step.

There was no data for quantifying the proportion of the building stock equipped with the considered kinds of airconditioning systems. Therefore, the method of Yamaguchi et al. (2017) was used to quantify the composition of the building stock in terms of the kinds of air-conditioning systems. The same predictor variables listed in Table 2 were considered, except for the kinds of air-conditioning systems.

\section{Identification of major combinations of energy conservation measures}

The following subsection describes the result of the application. Table 3 lists the support, confidence, and lift values and the number of samples with the combination of the considered measures shown in the first and second columns with a confidence larger than 0.16 derived in the association analysis conducted for office buildings. The results imply that the total heat exchanger, natural ventilation, and outdoor air intake control tend to be adopted independently. In addition to it, significant relations were observed between natural ventilation and the outdoor air intake control, the total heat exchanger and natural ventilation, and the outdoor air intake control system and the total heat exchanger.

Figure 3 shows the adoption rates of the combinations of energy conservation measures with high adoption rates in the ELPAC data. The figure indicates that a combination of energy conservation measures was adopted in approximately half of the sample buildings.

Table 3: Results of association analysis in office buildings.

\begin{tabular}{|c|c|c|c|c|c|}
\hline $\begin{array}{c}\text { Premise } \\
\text { part }\end{array}$ & $\begin{array}{c}\text { Conclusion } \\
\text { Part }\end{array}$ & Support & Confidence & Lift & $\mathbf{N}$ \\
\hline\{\} & $\{E S 1\}$ & 0.48 & 0.48 & 1.00 & 537 \\
\hline\{\} & $\{E S 2\}$ & 0.23 & 0.23 & 1.00 & 258 \\
\hline\{\} & $\{E S 3\}$ & 0.23 & 0.23 & 1.00 & 255 \\
\hline$\{E S 3\}$ & $\{E S 2\}$ & 0.22 & 0.96 & 4.13 & 245 \\
\hline$\{E S 2\}$ & $\{E S 3\}$ & 0.22 & 0.95 & 4.13 & 245 \\
\hline$\{E S 2\}$ & $\{E S 1\}$ & 0.16 & 0.70 & 1.44 & 180 \\
\hline$\{E S 1\}$ & $\{E S 2\}$ & 0.16 & 0.34 & 1.44 & 180 \\
\hline$\{E S 3\}$ & $\{E S 1\}$ & 0.16 & 0.70 & 1.45 & 179 \\
\hline
\end{tabular}

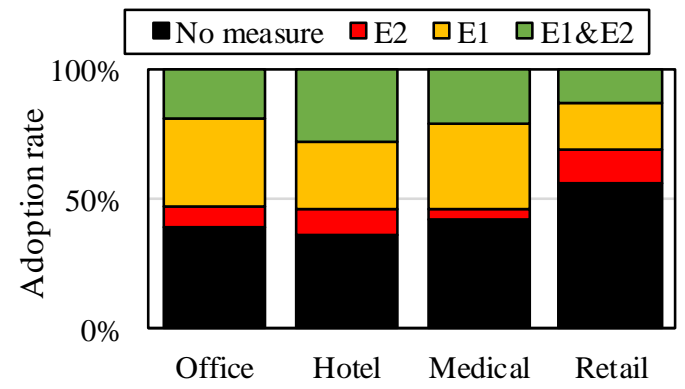

Figure 3: Adoption rates for combinations of energy conservation measures in ELPAC data.

The results of the association analyses for the other building uses were identical to the results for the office buildings.

\section{Logistic regression modelling}

Based on the association analysis, two logit models were developed. In this study, we assumed the combination of energy conservation measures listed in Table 4. Model 1 is an MNL model used for the adoption of measures related to air-conditioning systems. The adoption of the total heat exchanger (HEX) and outdoor air cooling system (OA) was considered. Model 2 is a BNL model used for the adoption of the variable water volume (VWV) control in the water delivery system.

Table 5 lists the regression coefficients, $p$ values, odds ratio (OR), and their $95 \%$ confidence intervals (CI) for the predictor variables (Table 2) estimated for the combinations of energy conservation measures for office buildings. The result indicates that the adoption rates of measures related to the air-conditioning system increase with an increase in the building's total floor area. The heating degree days (HDD) do not have a significant influence on the adoption of these measures. Year3 and Year4 have positive influences on all of the measures. This result implies that a larger number of energy conservation measures have been adopted in buildings constructed in more recent years.

Table 4: List of objective variables.

\begin{tabular}{|c|c|c|c|}
\hline Model & Abbreviation & \multicolumn{2}{|c|}{ Measures adopted in buildings } \\
\hline Model & NoES & \multicolumn{2}{|c|}{ No measures were adopted } \\
\hline 1 & HEX & \multirow{3}{*}{\multicolumn{2}{|c|}{$\begin{array}{l}\text { Total heat exchanger is adopted } \\
\text { in ventilation system. } \\
\text { Outdoor air cooling system is } \\
\text { adopted. } \\
\text { Both the total heat exchanger and } \\
\text { outdoor air cooling system are } \\
\text { adopted. }\end{array}$}} \\
\hline & $\mathrm{OA}$ & & \\
\hline & HEXandOA & & \\
\hline Model & NoVWV & \multirow{2}{*}{\multicolumn{2}{|c|}{$\begin{array}{l}\text { VWV control is not adopted. } \\
\text { VWV control is adopted in the } \\
\text { water delivery system. }\end{array}$}} \\
\hline 2 & VWV & & \\
\hline \multicolumn{4}{|c|}{ Table 5: Building size category. } \\
\hline Category & $\begin{array}{l}\text { Range in } \\
\text { total floor } \\
\text { area }\left[\mathbf{m}^{2}\right]\end{array}$ & Category & $\begin{array}{c}\text { Range in total } \\
\text { floor area } \\
{\left[\mathbf{m}^{2}\right]}\end{array}$ \\
\hline $\mathrm{CL} 1 / 2$ & $0-500$ & CL6 & $5,000-10,000$ \\
\hline CL3 & $500-1,000$ & CL7 & $10,000-20,000$ \\
\hline CL4 & $1,000-2,000$ & CL8 & $20,000-50,000$ \\
\hline CL5 & $2,000-5,000$ & CL9 & $50,000 \sim$ \\
\hline
\end{tabular}




\section{Estimation of composition of building stock}

We estimated the composition of the building stock in terms of the combinations of energy conservation measures. The results in this section are shown with the category of building size listed in Table 6. Figure 4 shows the estimated compositions of the building stock classified by building size. The figure indicates that the proportion of buildings equipped with energy conservation measures increases with an increase in the building's total floor area. The total heat exchanger proportion was estimated to be higher in office buildings than in the buildings with other uses. The proportion for the combination of the total heat exchanger (HEX) and natural ventilation $(\mathrm{OA})$ was higher in office and hotel buildings than in hospital and retail buildings. The proportion of buildings equipped with variable water volume control (VWV) increased with the building's total floor area in the hotel, hospital, and retail buildings, whereas it did not change significantly for office buildings. The VWV proportion was higher for hospitals than for buildings with other uses. Figure 5 shows the total floor area of the building stock classified by six regions sorted from the north (Hokkaido and Tohoku) to the south (Kyusyu and Okinawa). It was estimated that energy conservation measures were adopted in 59\% of the building stock. The combinations of energy conservation measures that included the total heat exchanger (HEX) occupied approximately $50 \%$, in which $13 \%$ adopted an outdoor air cooling system (OA), especially in large-scale buildings located in the Kanto and Kinki regions, where the building stock is densely constructed.

\section{Integration with UBEM using building shouls}

\section{UBEM for Japanese commercial building stock}

This section describes how an urban building energy model using building archetypes was used to estimate the total energy consumption of the Japanese commercial building stock with the four building uses. The details of the model are presented elsewhere (Kimura et al. 2017). The model classified the building stock by the meteorological condition (10 regional categories from north to south), building use (office, hotel, hospital, and retail), building size ( 9 categories listed in Table 6 for office, hotel, and hospital and 14 categories for retail use by retail business category), and configuration of the HVAC system (44 segments with different heat source and air conditioning system combinations). In total, the building stock was categorised into 10,480 segments. A building archetype was developed for each building stock segment. The building archetypes contained specific conditions for the building physical properties, equipment specifications, and operation. The building archetypes were used as an input dataset for EnergyPlus (DOE, 2016). The total energy consumption of the Japanese commercial building stock was quantified by aggregating the products of the intensity of the energy consumption quantified by the EnergyPlus simulation and the total floor area of the building stock segments.

Table 6: Results of regression analysis of energy conservation measures for office buildings.

\begin{tabular}{|c|c|c|c|c|c|c|c|}
\hline Measure & Variables & $\begin{array}{l}\text { Regression } \\
\text { coefficient }\end{array}$ & OR $(95 \%$ CI $)$ & Measure & Variables & $\begin{array}{l}\text { Regression } \\
\text { coefficient }\end{array}$ & OR $(95 \% \mathrm{CI})$ \\
\hline \multirow[t]{10}{*}{ HEX } & Constant & 0.116 & & \multirow{10}{*}{$\begin{array}{c}\text { HEX } \\
\text { and OA }\end{array}$} & Constant & -8.513 & \\
\hline & LogTFA & 0.243 & $1.28(1.14-1.42)$ & & LogTFA & $1.932^{\star \star \star}$ & $6.90(5.78-8.02)$ \\
\hline & HDD & -0.033 & $0.97(0.94-1.00)$ & & HDD & 0.044 & $1.04(0.88-1.23)$ \\
\hline & Year1 & & & & Year1 & & \\
\hline & Year3 & 0.094 & $1.10(0.99-1.21)$ & & Year3 & 0.081 & $1.08(0.99-1.17)$ \\
\hline & Year4 & 0.385 & $1.47(1.22-1.72)$ & & Year4 & 0.247 & $1.28(1.15-1.41)$ \\
\hline & CAV & -0.128 & $0.88(0.62-0.94)$ & & CAV & 0.629 & $1.88(1.63-2.13)$ \\
\hline & VAV & $-1.513^{* * *}$ & $0.22(0.15-0.29)$ & & VAV & 0.557 & $1.75(1.43-2.07)$ \\
\hline & FCU & 0.041 & $1.04(0.91-1.17)$ & & FCU & 0.054 & $1.06(0.99-1.13)$ \\
\hline & OHUCU & -21.500 & & & OHUCU & 0.002 & $1.00(0.97-1.03)$ \\
\hline \multirow[t]{10}{*}{$\mathrm{OA}$} & Constant & -10.820 & & \multirow[t]{10}{*}{ VWV } & Constant & -20.84 & \\
\hline & LogTFA & $1.976^{\star \star \star}$ & $7.21(5.12-9.00)$ & & LogTFA & -0.047 & $0.95(0.89-1.01)$ \\
\hline & HDD & 0.009 & $1.01(0.87-1.15)$ & & HDD & $-0.098^{*}$ & $0.91(0.87-0.95)$ \\
\hline & Year1 & & & & Year1 & -0.002 & $1.00(0.96-1.04)$ \\
\hline & Year3 & $0.981^{* *}$ & $2.67(1.78-3.56)$ & & Year3 & 20.83 & $\mathrm{OR}>100$ \\
\hline & Year4 & $0.931^{*}$ & $2.54(1.89-3.19)$ & & Year4 & 21.35 & OR $>100$ \\
\hline & CAV & $2.132^{\star \star *}$ & $8.43(6.94-9.92)$ & & CAV & 0.253 & $1.29(1.14-1.44)$ \\
\hline & VAV & $1.682^{* *}$ & $5.38(4.15-6.61)$ & & VAV & 0.504 & $1.66(1.45-1.87)$ \\
\hline & FCU & $2.176^{\star}$ & $8.81(7.03-10.59)$ & & FCU & 0.312 & $1.37(1.05-1.69)$ \\
\hline & OHUCU & 1.666 & $5.29(4.49-6.09)$ & & OHUCU & & \\
\hline
\end{tabular}



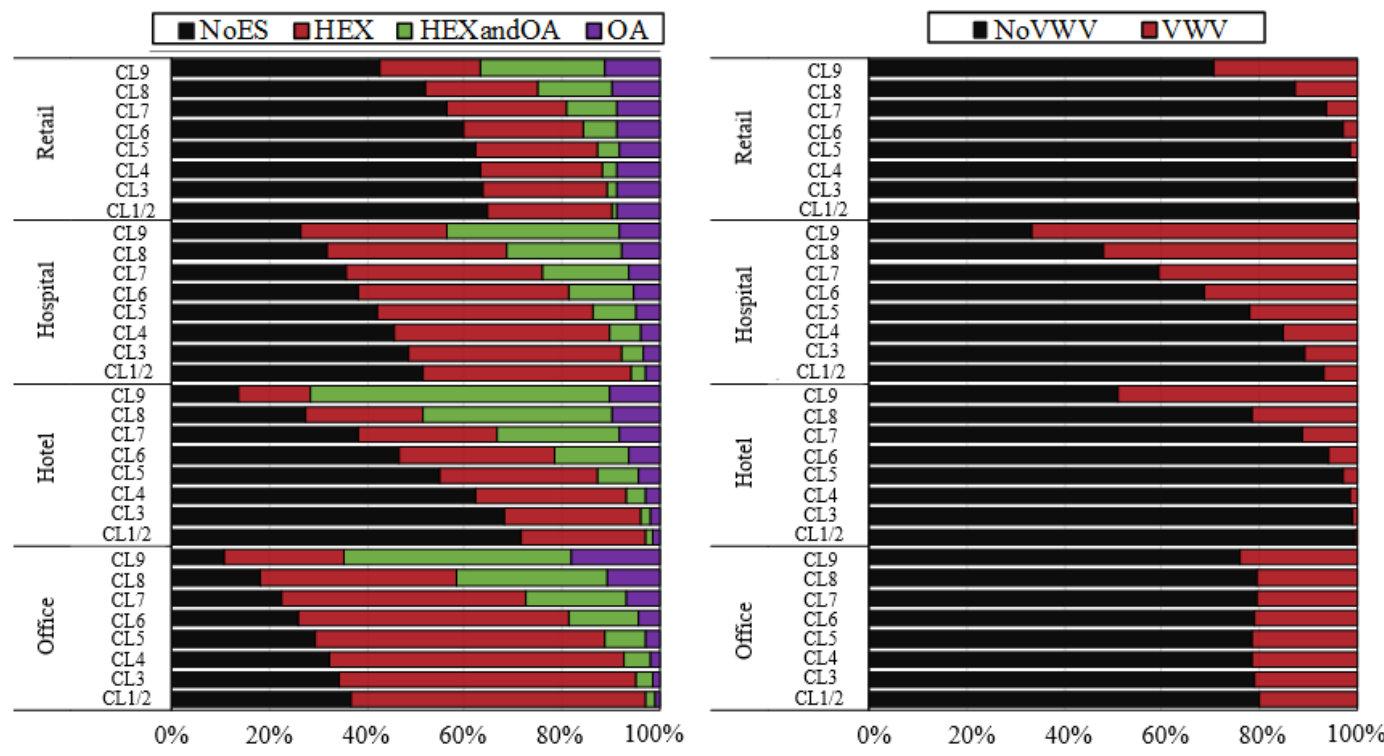

Figure 4: Proportion of total floor area of buildings equipped with energy conservation measures.

(left: related to air-conditioning system, right: VWV control)
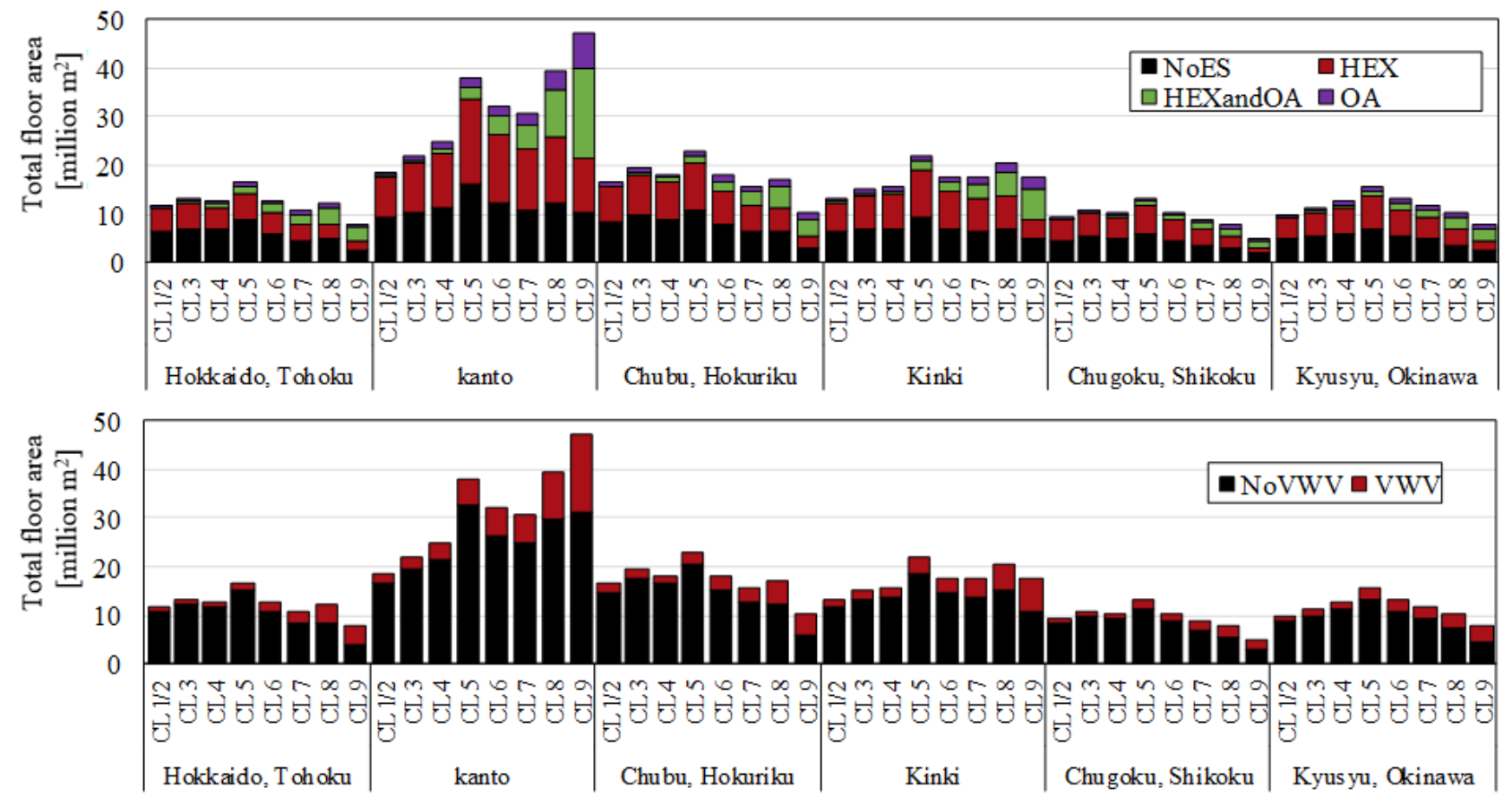

Figure 5: Total floor area of building stock.

Method to incorporate stock model of energy conservation measures into UBEM

The building segments were developed to consider the combinations of energy conservation measures. However, this method increased the number of building archetypes and the simulation time. To avoid the increases, we did not divide the building stock using the combinations of energy conservation measures. Instead, the adopted combination of energy conservation measures was randomly determined for each building archetype using the selection probabilities of the combinations quantified in the previous section for each building stock category. This method had the advantage of using the 10,480 building archetypes.
However, instead of avoiding the increases in the number of building archetypes and the simulation time, this method could result in a situation in which the stock of energy conservation measures assumed in the model deviated significantly from the result of the stock modelling. To evaluate whether this was the case, we compared the composition of the building total floor area estimated by the stock modelling method presented in the previous section and that assumed by the method with building archetypes.

Figure 6 shows the composition of the building stock in terms of the combinations. The results of the random sampling showed a good fit with the results of the stock modelling. This could be attributed to the large number of archetypes used in our building energy model. 


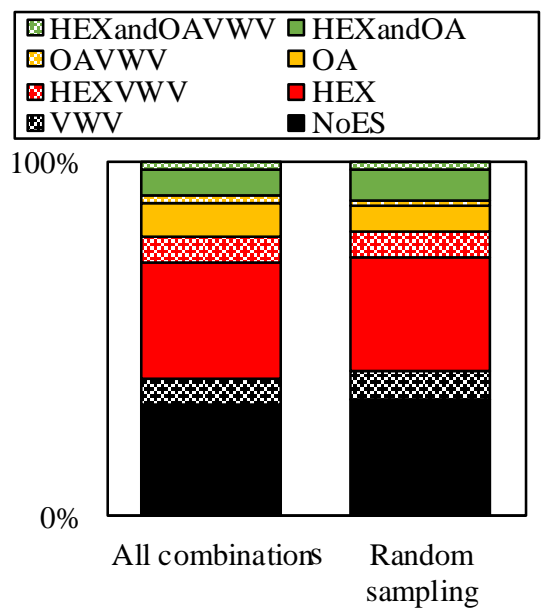

Figure 6: Share of energy conservation measures when all combinations considered and with random sampling.

\section{Evaluation of effect of considering stock of energy} conservation measures

Figure 7 shows the estimated building primary energy consumption values for office buildings with different building sizes (CL4, CL7, and CL5, see Table 6 for the building size classifications) and different HVAC system configurations. TBFCU indicates a centralised HVAC system using boilers as a heat source and compression chillers and fan coil units (FCUs) as an air-conditioning system. COMVAV assumed for the CL7 building is a centralised HVAC system that uses a combination of compression chillers and gas absorption chiller-heaters with air handling units using variable air volume (VAV) control. EHPMUL is a decentralised HVAC system that uses electricity-driven air source heat pumps.

Buildings with no energy conservation measures had the highest energy consumption values among the buildings. The energy conservation measures had different effects among the buildings as a result of the different building sizes and HVAC systems.

Figure 8 shows the estimated total primary energy consumption of the Japanese commercial building stock. Two simulation results are presented in this figure. The first is the result of the model in which no energy conservation measures were considered. The second case shows the result estimated by the model considering the stock of energy conservation measures. The overestimation that resulted from a lack of knowledge of the energy conservation measures was estimated to be 3.5 $\mathrm{PJ}$, which was equivalent to $3 \%$ of the total primary energy consumption.

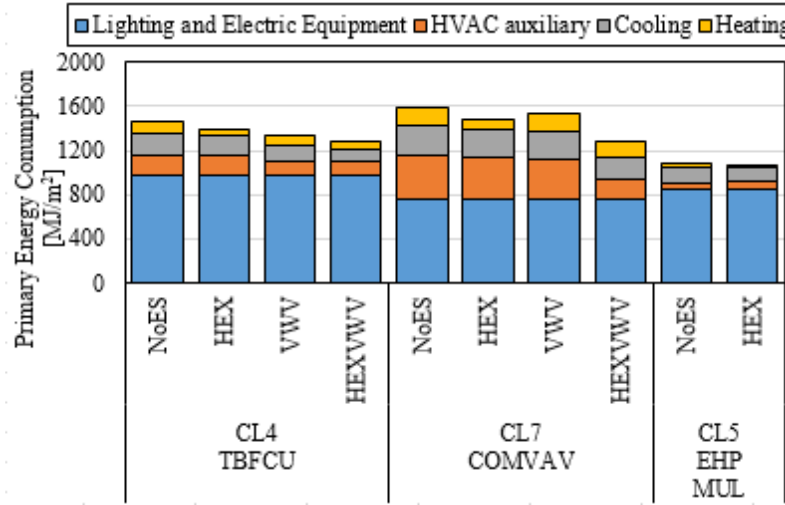

Figure 7: Estimated annual primary energy consumption.

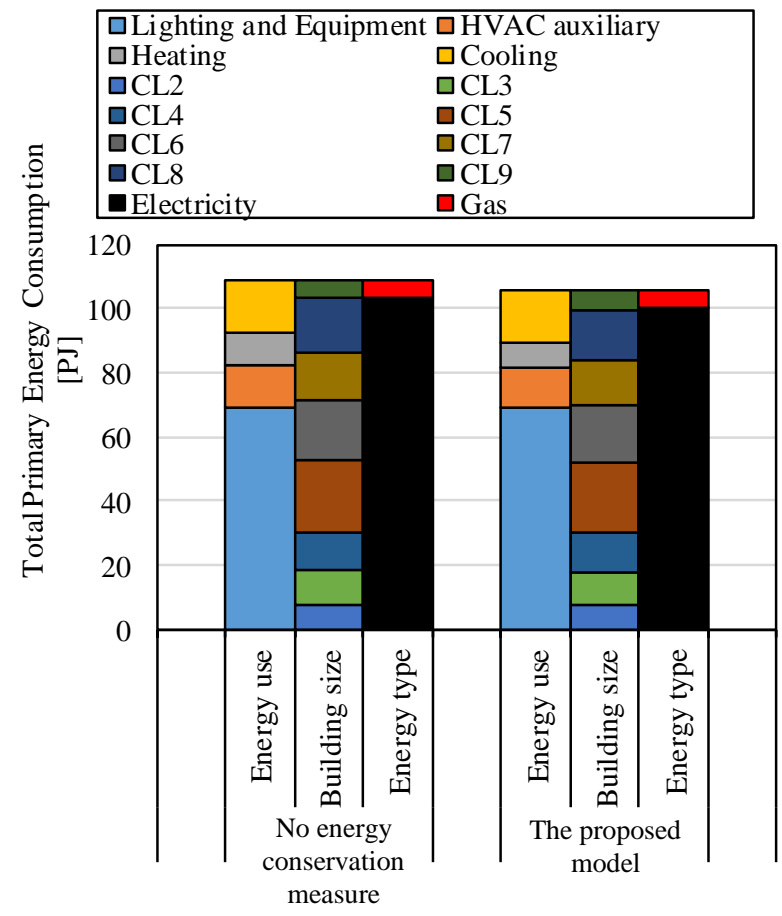

Figure 8: Total primary energy consumption values of Japanese commercial buildings.

\section{Discussion and conclusion}

We presented a stock modelling method to consider buildings with energy conservation measures and an urban building energy modelling method to integrate the result of the stock modelling method. These methods were demonstrated using the Japanese commercial building stock. The method can be characterised by the following:

1. identification of combinations of energy conservation measures,

2. logistic regression modelling of the selection of combinations of energy conservation measures in a building,

3. application of the logistic regression models to quantify the adoption probabilities of the combinations in the building stock classified by the meteorological conditions, building use, size, and HVAC systems, and 
4. random sampling of the measures to determine the measures considered in building archetypes representing the building stock segments.

The energy modelling results showed that the consideration of the energy conservation measures was equivalent to $3 \%$ of the total primary energy consumption for the Japanese commercial building stock.

\section{Acknowledgement}

This work was supported by JSPS KAKENHI Grant Number JP16H04463 and JST CREST Grant Number JPMJCR15K4, Japan.

\section{Reference}

Agrawal, R. \& Srikant, R. (1994). Fast Algorithms for Mining Association Rules. Proceedings of $20^{\text {th }}$ International Conference on Very Large Databases. Santiago (Chile), 12-15 September 1994.

Andrews, C. J., \& Krogmann, U. (2009). Explaining the adoption of energy-efficient technologies in U.S. commercial buildings. Energy and Buildings, 41(3), 287-294. http://doi.org/10.1016/j.enbuild.2008.09.009

DOE (Department of Energy) of US, EnergyPlus version $8.6,2016$ https://energyplus.net/downloads

Fernandez, N., Katipamula, S., Wang, W., Xie, Y. \& Zhao, M. (2018). Energy savings potential from improved building controls for the US commercial building sector. Energy Efficiency 11, 393-413

Jridi, O., Aguir Bargaoui, S., \& Nouri, F. Z. (2015). Household preferences for energy saving measures: Approach of discrete choice models. Energy and Buildings, 103, 38-47. http://doi.org/10.1016/j.enbuild.2015.06.013

Kimura, S., Yamaguchi, Y., Kim, B., Miyachi, Y., Kou, Y. \& Shimoda, Y. (2017). Urban Scale Energy Demand Modelling of Commercial Building Stock Considering the Variety of HVAC System Configuration, Proceedings of $16^{\text {th }}$ IBPSA International conference and exhibition, San Francisco (USA), 7-9 August 2017

Kontokosta, C. E. (2016). Modeling the energy retrofit decision in commercial office buildings. Energy and Buildings, 131, 1-20. http://doi.org/10.1016/j.enbuild.2016.08.062

Statistical Bureau of Japan, e-Stat. The Result of the survey on Land and Buildings, (2017), Published in http://www.estat.go.jp/SG1/estat/GL0802010.do?_toGL08020101 _\&tstatCode $=000001020939$

Swan, L. and Ugursal, V. (2009). Modeling of end-use energy consumption in the residential sector: A review of modeling techniques. Renewable and Sustainable Energy Reviews, Vol. 13, 1819-1835
Wang, F., Li, K., Duić, N., Mi, Z., Hodge, B.-M., Shafiekhah, M. \& Catalão, J.P.S. (2018). Association rule mining based quantitative analysis approach of household characteristics impacts on residential electricity consumption patterns. Energy Convers. Manag. 171, 839-854. https://doi.org/10.1016/J.ENCONMAN.2018.06.017

Yamaguchi, Y. \& Shimoda, Y. (2010). District-scale simulation for multi-purpose evaluation of urban energy systems. Journal of Building Performance Simulation, 3(4), 289-305. https://doi.org/10.1080/19401491003746621

Yamaguchi, Y., Miyachi, Y. \& Shimoda, Y. (2017). Stock modelling of HVAC systems in Japanese commercial building sector using logistic regression. Energy and Buildings 152, 458-471 